\section{PKS}

PUBLIC

KNOWLEDGE

PROJECT

\section{REVISTA ENSINO DE GEOGRAFIA}

(RECIFE)

http://www.revista.ufpe.br/ensinodegeografia $\underline{\text { OJS }}$

SYSTEMS

\title{
RECURSOS DIDÁTICOS NO ENSINO FUNDAMENTAL: UMA PROPOSTA METODOLÓGICA A PARTIR DO SUBPROJETO DE GEOGRAFIA PIBID/UEPB
}

\author{
Dalila Arruda Nascimento \\ Graduada em Geografia pela Universidade Estadual da Paraíba (2017). Tem experiência na \\ área de Geografia, com ênfase em Educação Geográfica. Participou do Programa \\ Institucional de Bolsas de Iniciação à Docência (PIBID), Subprojeto de Geografia da \\ Universidade Estadual da Paraíba (UEPB). \\ arnadalila@hotmail.com
}

\section{Josandra Araújo Barreto de Melo}

Professora Doutora do curso de Geografia da Universidade Estadual da Paraíba, Coordenadora do Curso de Geografia, modalidade EAD/UAB/UEPB e está na coordenação do curso de Especialização em Ensino de Geografia/CEDUC/UEPB. Líder do Grupo de Pesquisa Ensino de Geografia/UEPB.

ajosandra@yahoo.com

\section{Jonas Marques da Penha}

Professor Especialista na área de ensino de Geografia. Mestrando do Programa de Pósgraduação em Educação Profissional e Tecnológica/IFPB. Professor efetivo da Rede

Estadual de Educação da Paraíba. jonas.marques@hotmail.com

RESUMO: O presente trabalho é resultado de experiências oriundas das intervenções em sala de aula na vigência do subprojeto de Geografia/PIBID/UEPB, na E. E. E. F. M ${ }^{a}$ E. Oliveira de Almeida, zona sul da cidade de Campina Grande - PB. A proposta apoia-se em refletir sobre o uso e produção dos recursos didáticos como ferramentas metodológicas no ensino de Geografia. As intervenções transcorreram na perspectiva colaborativa, por meio de projetos pedagógicos sob a luz da pesquisa-ação, apoiadas em autores como Tripp (2005), Franco (2012). Propusemo-nos em diversificar e produzir recursos didáticos como estratégias de interação e identificação dos alunos com os temas propostos na grade curricular da disciplina. Conhecer e respeitar as identificações e limitações dos alunos são pressupostos para efetivar melhor rendimento no processo de ensino aprendizagem. Com isso, buscamos demonstrar que os recursos didáticos podem auxiliar e contribuir com o ensino de Geografia e para uma formação crítica e reflexiva no cotidiano escolar.

Palavras-chave: Ensino de Geografia. Recursos Didáticos. Ensino. 
TEACHING RESOURCES IN FUNDAMENTAL TEACHING: A METHODOLOGICAL PROPOSAL FROM THE GEOGRAPHY SUBPROJECT PIBID / UEPB

\begin{abstract}
The present work is the result of experiences from classroom interventions during the Geography / PIBID / UEPB subproject, in E. E. E. M ${ }^{\mathrm{a}}$ E. Oliveira de Almeida, south zone of the city of Campina Grande - PB. The proposal is based on reflecting on the use and production of didactic resources as methodological tools in Geography teaching. The interventions took place in a collaborative perspective, through pedagogical projects under the light of action research, supported by authors such as Tripp (2005), Franco (2012). We proposed to diversify and produce didactic resources as strategies for interaction and identification of students with the themes proposed in the curriculum of the course. Knowing and respecting the identifications and limitations of the students are presupposed to promote involvement in the process of teaching learning. Demonstrating that the didactic resources can help and contribute with the teaching of Geography and for a critical and reflexive formation.
\end{abstract}

Keywords: Geography Teaching. Didactic resources. Teaching.

\title{
INTRODUÇÃO
}

No contexto atual de sociedade globalizada as mudanças são constantes em todos os setores e, na educação, não deve ser diferente, se fazendo imprescindível acompanhar os processos de renovação e reestruturação desse campo. No entanto, mesmo diante das renovações ocorridas, a Geografia escolar ainda permanece arraigada aos métodos clássicos, de cunho mnemônico, pouco motivador que a levam a não atingir os seus objetivos enquanto disciplina.

O cotidiano escolar apresenta-se como espaço de heterogeneidades, ou seja, onde as múltiplas culturas se convergem, e as representações sociais afloram, e no qual os discentes constroem identidade e buscam autonomia sendo, portanto, necessário considerar o multiculturalismo deste ambiente e adotar metodologias integradoras, viabilizando uma aprendizagem significativa que busque distanciar as práticas clássicas ainda presentes na atualidade.

Ressalta-se que este trabalho propõe refletir sobre as condutas metodológicas e o uso de recursos didáticos no processo de ensino e aprendizagem nas aulas de Geografia, tomando como experiência as práticas desenvolvidas em duas turmas do Ensino Fundamental da Escola Estadual de Ensino Fundamental Maria Emília Oliveira de Almeida, no âmbito do Subprojeto PIBID/DG/UEPB, durante o ano de 2016 e 2017. Os projetos tiveram como 
objetivo aproximar os conteúdos curriculares ao espaço vivido dos alunos, utilizando e produzindo recursos didáticos que pudessem contribuir nas aulas.

A relevância deste trabalho apoia-se na perspectiva da demonstração de experiências vividas mediante a utilização dos variados recursos didáticos, a fim de perceber a eficácia ou não do uso no processo de ensino-aprendizagem da disciplina de Geografia, buscando refletir sobre o potencial dos recursos didáticos como mediadores para superação de práticas clássicas de ensino.

Para alcançar os objetivos propostos, o trabalho ancora-se na perspectiva da pesquisa qualitativa, apoiada pelas práticas da pesquisa-ação, a partir da integração dos agentes envolvidos, as avaliações e o rever contínuo da prática e dos resultados através dos projetos de intervenção pedagógicas. Visando o aprimoramento e consolidação de práticas significativas à formação inicial.

\title{
RECURSOS DIDÁTICOS ENQUANTO FERRAMENTAS PARA DINAMIZAR O ENSINO DE GEOGRAFIA
}

A necessidade de formação, conhecimento, domínio de técnica, capacidade de análise são cada vez mais importantes para acompanhar a sociedade atual. Neste contexto, a escola deveria passar segurança e fornece o suporte necessário para a consolidação de tais cognições. Pensar a escola e sua gestão torna-se necessário, uma vez que os tempos de crise são variados os problemas que afetam diretamente tal instituição.

Como aborda Cavalcanti (2010, p. 82):

\begin{abstract}
Pensar a escola e sua gestão não apenas em uma dimensão teórico-racional e burocrática, pois a escola deve ser entendida como uma comunidade de aprendizagem, em que devem ser predominantes as práticas educativas, com vistas a promoção do desenvolvimento mental e da formação da personalidade dos alunos.
\end{abstract}

Tais condições, seguindo a ideia da autora, somente serão alcançadas se tornamos o espaço escolar uma unidade de superação de obstáculos, e em seu cotidiano possa desenvolver práticas de aprendizagem que superem as barreiras físicas do ambiente escolar. Dessa forma, a escola, e não somente os professores em sala de aula, deverão ser responsáveis pelo envolvimento dos alunos no processo de aprendizagem.

Castrogiovanni (2010, p. 13), argumenta: 
Existe ainda pouca aproximação da escola com a vida, com o cotidiano dos alunos. A escola não se manifesta atraente frente ao mundo contemporâneo, pois não dá conta de explicar e textualizar as novas leituras de vida. (...) a escola parece ser homogênea, transparente e sem brilho no que se refere a tais características. É urgente teorizar a vida, para que o aluno possa compreendê-la e representá-la melhor e, portanto, viver em busca de seus interesses.

A escola neste contexto, deve se volta para o desenvolvimento de práticas que percebam a heterogeneidade de seus alunos, trabalhando junto com os professores em sala de aula, fazendo com que o discente possa se sentir parte da instituição, promovendo um sentimento de pertencimento, um lugar onde ele seja acolhido e possa mostrar e lapidar suas habilidades.

Dessa forma, cabe não somente ao professor ser o agente responsável pela aprendizagem dos seus alunos, e sim um trabalho que se desenvolva em conjunto, por meio de uma gestão capacitada para promover situações de aprendizagem mais amplas, que envolva e comprometa os mais variados setores da instituição, visando à construção de conhecimentos por meio das mais variadas fontes.

Os recursos didáticos se apresentam nesta conjuntura, como facilitadores do processo de ensino e aprendizagem, capazes de mediar diálogos e promover uma maior interação entre os agentes envolvidos nestes processos educacionais. Enquanto ferramentas pedagógicas os recursos se consolidam e promovem a construção de conhecimentos geográficos, na escola, capazes favorecer a percepção dos alunos em relação às espacialidades configuradas por meio das práticas sociais cotidianas.

É sabido que os avanços teóricos têm chegado lentamente à prática escolar, que permanece arraigada em concepções teóricas superadas, assim, ao contemplar a utilização de recursos didáticos para auxiliar e dinamizar a prática tem sido uma tendência dos professores na atualidade. Levando em consideração também, a necessidade de acompanhar o desenvolvimento da sociedade, que cada vez mais utilizam de variadas linguagens para promover o desenvolvimento de habilidades.

Tal como, Pontuschka (2009), coloca ao refletir sobre as representações e linguagens no ensino de Geografia, neste ensaio a autora reforça a ideia de que há uma necessidade que deve ser considerada em relação ao uso dos recursos didáticos, seja na escola, seja em outras vertentes, visto que, por meio deles os horizontes do conhecimento se ampliam.

Os recursos didáticos - ou empregados como propostas didáticas -, na qualidade de mediadores do processo de ensino-aprendizagem nos diferentes níveis, obedecem em sua seleção e utilização, a alguns critérios, tais como a adequação aos objetivos 
propostos, aos conceitos e conteúdos a ser trabalhados, ao encaminhamento do trabalho desenvolvido pelo professor em sala de aula e às características da turma, do ponto de vista das representações que trazem para o interior da sala de aula. (PONTUSCHKA, 2009, p. 215-216).

Assim, é primordial que se estabeleçam critérios, que haja planejamento e organização do professor ao utilizar de tais ferramentas.

Corroborando, Souza (2007):

O papel do professor neste processo é de vital importância para que o uso de tais recursos alcance o objetivo proposto. $\mathrm{O}$ professor deve ter formação e competência para utilizar os recursos didáticos que estão a seu alcance e muita criatividade, ou até mesmo construir juntamente com seus alunos, pois, ao manipular esses objetos a criança tem a possibilidade de assimilar melhor o conteúdo. (P. 111)

Nesta conjuntura, torna-se perceptível que o professor deve estar preparado para manusear e assegurar a eficácia do uso das ferramentas didáticas em suas aulas. E isso lhes deve ser assegurando durante o processo de formação.

Novamente apoiando-se na autora (PONTUSCHKA, 2009, p.216), pode-se inscrever como recursos didáticos "vários tipos de materiais e linguagens, como: mapas, gráficos, imagens de satélite, literatura, música, poemas, filme, videoclipe, jogos, livro didáticos, paradidáticos". Estes materiais podem ser manuseados em sala de aula para promover maior ressignificação aos temas trabalhados pela disciplina.

Fiscarelli (2008), reforça:

Por recursos didáticos, entende-se o conjunto de materiais que, ao serem utilizados para fins pedagógicos, buscam uma melhor mediação no processo de ensinoaprendizagem, podendo ser todo tipo de objeto material (giz, livro didático, maquete, globo terrestre, entre outros) ou imaterial (tonalidade da voz e expressões corporais); e também aqueles direcionados aos formatos eletrônicos, tais como microcomputadores, datashow e Global Position System (GPS). (p.56)

Dessa forma, sob a luz das referências utilizadas entende-se como recurso didático todo material utilizado como auxilio no processo de ensino e aprendizagem. Com isso, os recursos didáticos permitem um melhor aproveitamento na abordagem dos temas/conteúdos, além de promover uma maior interação entre os agentes envolvidos, se forem utilizados de forma adequada.

Com a utilização de recursos didático-pedagógicos, pensa-se em preencher as lacunas que o ensino clássico geralmente deixa, e com isso, além de expor o conteúdo de uma forma diferenciada, faz dos alunos participantes do processo de aprendizagem, uma vez que, também podem ser produzidos pelos próprios discentes. 
Nesse sentido as possibilidades são ainda mais amplas, os alunos são desafiados a elegerem ferramentas para auxiliar no seu próprio processo de aprendizagem, sempre auxiliados pelo professor que durante o processo deverá instigar as habilidades dos estudantes, valorizando as representações e autonomia dos mesmos.

Salete Eduardo de Souza, acredita que:

\begin{abstract}
O material a ser utilizado deve proporcionar ao aluno o estimulo à pesquisa e a busca de novos conhecimentos, o propósito do uso de materiais concretos no ensino escolar é o de fazer o aluno a adquirir a cultura investigativa o que o preparará para enfrentar o mundo com ações práticas sabendo - se sujeito ativo na sociedade. (SOUZA, 2007, p. 111).
\end{abstract}

A autora nos mostra o quão importante é refletir e ter consciência do prejuízo que pode causar o uso inadequado dos recursos didáticos em sala de aula. O material didático deve ficar como recurso auxiliar, que promova a interação entre professor-aluno e conhecimento, sendo necessário que haja o planejamento das aulas e das atividades que priorizem resultados positivos. $\mathrm{O}$ uso não deve ser apenas vinculado à dinamicidade que o recurso poderá proporcionar na aula. A proposta é fazer com que o sujeito consiga assimilar o conteúdo e seja capaz de ressignificá-lo em fases posteriores da aprendizagem.

Pelo prisma de Fantin (2005):

É preciso fugir da armadilha de aulas-espetáculo, em que muitos materiais são manuseados, observados, até construídos pelos alunos, sem que haja compreensão do que estão fazendo nem clareza dos objetivos daquela atividade. Isso acontece quando o professor não planeja suas aulas e pensa nos recursos como argumentos autossuficientes para a aprendizagem. (P. 101).

Um alerta aos docentes. Recursos didáticos metodológicos são ferramentas de caráter duplo, e por isso, deve-se considerar que sejam usados de forma planejada, objetivando facilitar ou potencializar a aprendizagem. É preciso que tenhamos cautela e responsabilidade ao inserir essas propostas em nossos planos de aula, eles não são autossuficientes.

O encaminhamento metodológico deve contemplar o momento em que o aluno elabora e expressa - por escrito, oralmente ou por meio das mais diversas linguagens - a síntese do conhecimento construído. E diante das dificuldades que encontramos ao ensinar a Geografia, torna-se plausível eleger metodologias que possam viabilizar o interesse dos alunos.

EXPERIÊNCIAS DOCENTES NO SUBPROJETO DE GEOGRAFIA/PIBID/UEPB 
As experiências docentes socializada nesse trabalho ocorreram nas intervenções entre o segundo semestre de 2016 e o primeiro semestre de 2017 contemplando respectivamente as turmas do ensino fundamental II. A proposta da utilização e produção de recursos surtiram resultados positivos com a primeira turma, dando margem para que a mesma tendência fosse seguida, a fim de aperfeiçoar as práticas e contemplar novas abordagens na construção dos conhecimentos geográficos.

Figura 01. Mapa de localização da área de estudo.

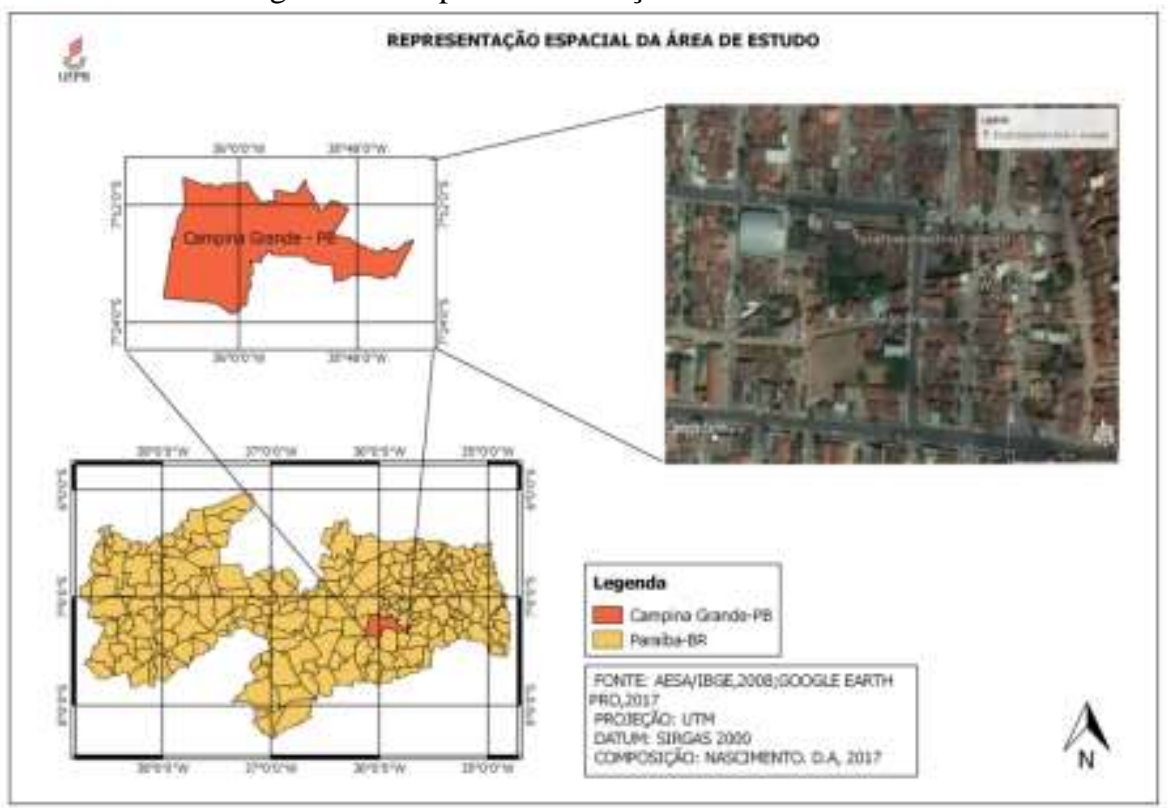

Fonte: Dalila Arruda, 2017.

Orientado a partir da pesquisa qualitativa, ancorando-se na utilização de técnicas que incluíram pesquisas bibliográficas e pesquisa-ação. O desenvolvimento teve como objeto de pesquisa e de intervenções as turmas do $8^{\circ} \mathrm{B}$ e $9^{\circ} \mathrm{A}$, objetivando-se analisar as contribuições do uso de recursos didáticos (utilização e produção) no processo de ensino e aprendizagem nas aulas de Geografia.

Sobre a prática da pesquisa-ação, Guido Irineu Engel:

A pesquisa-ação procura unir a pesquisa à ação ou prática, isto é, desenvolver o conhecimento e a compreensão como parte da prática. É, portanto, uma maneira de se fazer pesquisa em situações em que também se é uma pessoa da prática e se deseja melhorar a compreensão desta. (ENGEL, 2000, p. 182)

Isto posto, compreende-se que a pesquisa-ação configura um processo de concomitância de pesquisa e ação, de pesquisadores e de práticas. Nota-se que o objetivo 
desta forma de investigação é a formação mais crítica de professores. (FRANCO, 2012, p. 106) considera a pesquisa-ação uma "investigação autorreflexiva que visa à compreensão, à análise e à transformação das próprias práticas".

Corroborado por Tripp (2005, p. 445):

A pesquisa-ação educacional é principalmente uma estratégia para o desenvolvimento de professores e pesquisadores de modo que eles possam utilizar suas pesquisas para aprimorar seu ensino e, em decorrência, o aprendizado de seus alunos, $[\ldots]$.

Portanto, compreendemos que a efetivação de uma prática voltada para o aprimoramento e autorreflexão da práxis, contribui para a consolidação de profissionais mais preparados para as novas demandas contemporâneas do ambiente escolar. Este tipo de pesquisa na docência contribui para rupturas no processo tecnicista na profissão, promovendo a possibilidade de ressignificação das relações entre teoria e prática.

Corroborando para a consolidação do que se chama de "espirais cíclicas" (FRANCO, 2012, p. 121), ao contemplar o exercício continuo das diversas etapas vivenciadas durante a pesquisa, buscando o aprofundamento e novas reflexões à pesquisa. Estas espirais possibilitam um retorno ao experimentado, revisões e acerto de novas perspectivas e possibilidades, sendo um processo, sobretudo pedagógico, composto e partilhado.

\section{Intervenções Didático-Pedagógicas}

Após a definição das turmas é comum à observação e aplicação de questionário de diagnóstico. Por meio destes, são analisados perfil de turma, nível de conhecimentos dos discentes em relação a alguns temas da disciplina, identificação com a ciência, e pretensões em relação ao desenvolvimento de atividades que viriam a ser realizadas, assim como poderiam sugerir ideias para o ensino da Geografia em sala de aula.

Mediante a aplicação questionário pôde-se perceber que a maioria dos alunos não detinha de muitas habilidades em relação aos conteúdos investigados, e não apresentavam clareza em suas respostas na maioria das questões discursivas se restringiam a justificar suas colocações. No que tange as aspirações e sugestões de atividades, os discentes apresentaram argumentos voltados para a utilização de mapas e de aulas mais dinâmicas, fazendo uso de imagens, filmes, slides e aula de campo. 
Destarte, buscamos através da análise dos questionários, fornecer um retorno aos discentes, e fora no suporte dos recursos didáticos que nos apoiamos para conseguir promover aulas de Geografia mais significativas aos estudantes.

Neste trabalho apresentaremos os projetos pedagógicos de intervenção da turma do $9^{\circ}$ ano "A" do ensino fundamental, estabelecida no turno da manhã, comportando uma média de 25 discentes. Junto à turma em destaque, aplicou-se o questionário de diagnósticos que orientou o direcionamento de algumas das atividades conforme a carência que foi observada por meio de análise.

A o quadro abaixo, apresenta um quadro com a descrição dos recursos didáticos utilizados e produzidos durante as intervenções referentes ao ano de 2017.

Quadro 01. Materiais didáticos.

\begin{tabular}{|l|l|l|}
\hline Título: "Um Zoom nos $\begin{array}{l}\text { continentes: Ásia e África } \\
\text { e as regiões polares, } \\
\text { numa perspectiva global- } \\
\text { local”. }\end{array}$ & Recursos utilizados & Recursos produzidos \\
\cline { 2 - 3 } & Globo terrestre & Cartazes pedagógicos \\
\cline { 2 - 3 } & Mapa-múndi & Representações gráficas de mapas \\
\cline { 2 - 3 } & Imagens & Quadrinhos \\
\cline { 2 - 3 } & Slides & Charges \\
\cline { 2 - 3 } & Atlas Geográfico & Paródia \\
\hline & Vídeo & Slides \\
\cline { 2 - 3 } & Livro didático & Vídeo reportagens \\
\hline
\end{tabular}

Fonte: Dalila Arruda, 2017.

\section{Ações orientadas e organizadas por temas da grade curricular e seguidas em etapas}

\section{Tema: Continente Asiático}

- $\quad$ Primeira - Abordando o tema "Continente asiático", realizou-se uma apresentação do projeto, por meio de aula expositiva e dialogada, com enfoque nas categorias de análise da Geografia, que ao longo do projeto seriam exploradas. Utilizou-se imagens dispostas no livro didático e mapa-múndi como recursos para sistematizar melhor o conteúdo.

- $\quad$ Segunda - Utilizou-se o mapa-múndi e o globo para auxiliar o processo de ensino e aprendizagem. Traçando no mapa a abrangência territorial do continente, pôde-se perceber sua grande extensão e refletir sobre as diferentes paisagens do continente, fazendo através do globo a explicação das zonas térmicas que fazem com que possamos ter paisagens semelhantes no Brasil. Fora proposto um trabalho em grupo sobre físicos naturais do continente, no qual os discentes produzissem o recurso para auxiliar sua apresentação. 
- Terceira - Corresponde às apresentações do que fora proposto. O primeiro grupo organizou a turma em semicírculo, e enriqueceu a apresentação sobre os "climas da Ásia" através de cartaz pedagógico e imagens. O grupo seguinte abordou o tema "vegetação", fazendo uso de imagens, que destacavam paisagens peculiares da diversidade vegetal do continente.

- Refletiu-se sobre a disponibilidade de água no território asiático, assim como as possíveis consequências da escassez hídrica em algumas regiões do continente. Os alunos fizeram uso de cartazes para materializar as pesquisas realizadas.

- O livro didático foi utilizado como sugestão da aluna, que realizou um estudo dirigido, com auxílio da bolsista. Diante da finalização das apresentações realizou-se um Quiz Geográfico, com perguntas sobre os temas abordados ao longo das apresentações.

- Quarta - Iniciou-se o conteúdo sobre o "Oriente Médio e os conflitos territoriais na região". Utilizou-se o mapa mudo para o desenvolvimento da atividade gráfica e de pintura do mapa, assim como a criação de legendas para os recursos produzidos. Após a criação de mapas explicativos fora realizado a socialização de ideias a respeito do tema.

\section{Tema: Continente Africano}

- Primeira - Corresponde ao início das atividades a respeito do "Continente africano". Utilizando de imagens, analisaram-se paisagens das riquezas do continente e suas diversidades naturais. Após, fora delimitada no mapa a localização do continente, e novamente o globo ofereceu suporte para articulação entre escalas.

- Segunda -Trabalhamos com imagens, foram distribuídas entre os alunos imagens de diferentes paisagens e contextos, nem todas correspondiam ao continente em destaque, justamente para que os alunos refletissem sobre a paisagem, e no mapa-múndi colasse a imagem, identificando o continente/país do qual, em sua visão a foto pertencia;

- $\quad$ Para ampliar esse olhar, fora proposto que os alunos pesquisassem sobre um país do continente, e o apresentasse em sala por meio de vídeo ou slides;

\section{Tema: Regiões Polares}

- Etapa única - O conteúdo "Regiões Polares" iniciou-se com a proposta de articulação entre escalas. O uso de slides, imagens, globo, vídeo documentário, e produção de charges e fotografias, forma eleitos como recursos para desenvolvimento da prática. Por meio dos slides apresentamos o tema, analisou-se imagens e foi feito experiências com o uso do globo para explicar as regiões. 
- $\quad$ E com o objetivo de realizar um trabalho com fotografias em escala local, o tema foi trabalhado na perspectiva dos impactos ambientais.

Nas abordagens teóricas dos conteúdos utilizamos variados recursos e linguagens para o apoio das práticas. Assim, à medida que foram oferecidas sugestões, cada grupo se identificaram com um determinado material a ser produzido e assim desenvolveram-se as atividades.

Como se pudera verificar através das etapas de cada tema as ações pedagógicas transcorreram obedecendo à grade curricular proposta para a turma. Nesse contexto, a proposta continuou na perspectiva de inserção de uma variedade de recursos para potencializar a aprendizagem geográfica em sala de aula, como orienta a resignificação das espirais cíclicas da pesquisa-ação, fundamentado por Maria Amélia S. Franco (2012):

[...] o método da pesquisa-ação deve contemplar o exercício contínuo de suas diversas etapas, por meio das espirais cíclicas: planejamento - ação - reflexão pesquisa - ressignificação - replanejamento em um movimento que busca ações cada vez mais ajustadas às necessidades coletivas. (FRANCO, 2012, p. 121)

Diante da esclarecedora colocação, pode-se compreender o quanto a pesquisa-ação oferece subsídios para o desenvolvimento das práticas pedagógicas no ensino. As ações apresentadas no ciclo visam promover novas reflexões para o aprofundamento da pesquisa.

Neste sentido os recursos que foram implantados neste momento da pesquisa surgiram com a proposta colocar em prática esse movimento proposto pela pesquisa-ação, e de aproximar conteúdos e torná-los significativos aos discentes. Apoiando as aulas na perspectiva da articulação de escalas, e principalmente, mas não exclusiva, na categoria paisagem, desenvolveu-se novas reflexões e práticas articulada as necessidades da turma.

Torna-se relevante pensarmos o uso do globo terrestre em sala de aula, tendo em vista que o mesmo foi utilizado na maioria das aulas durante as intervenções, justamente pelo fator de acesso e aceitação dos alunos. Schäffer, Kaercher, Goulart e Castrogiovanni (2012), na obra Um globo em suas mãos, argumentam a importância, a forma de uso e as dificuldades do uso do globo na escola.

Nisso, argumentam:

Na Geografia escolar, um globo deveria estar presente ao serem trabalhados temas como orientação e localização, para apresentar a rede de coordenadas geográficas, para dar concretude a noções bastante abstratas quanto à posição da Terra no espaço e suas relações no sistema planetário, para esclarecer a diferença de representação espacial e as distorções decorrentes da projeção de um sólido (a Terra) sobre um plano (o papel de um mapa) e para explicar a relação entre a esfericidade da Terra e a diversidade ambiental, especialmente a climática. [...] $\mathrm{O}$ globo é recurso apropriado para mostrar fluxos espaciais a grande distância. Sem um globo terrestre, 
teremos dificuldades para trabalhar temas que necessitam de uma exposição clara de distâncias e posições no planeta. (p. 21-22).

Por meio desta colocação nota-se que o uso desta ferramenta proporciona inúmeras aquisições sobre os conhecimentos geográficos. Durante o projeto de intervenção usamos o globo na abordagem de outros conteúdos, além do continente asiático. A dinâmica mais expressiva proporcionada pelo uso do globo foi referente ao tema: "Regiões Polares", como está descrito nas ações.

Apoiada pela ideia de Bulgraen (2010), a proposta reflete espontaneamente no sentido de considerar as representações sociais dos alunos, estes que trazem para sala de aula suas experiências sociais acumuladas em seu contexto social, de modo a construir a partir daí um ambiente escolar acolhedor em que o estudante se sinta parte do todo e esteja totalmente aberto a novas aprendizagens.

Deste modo, podemos mostrar que o processo de ensino e aprendizagem é na verdade um compartilhamento de informações e de experiências, que são refletidas e ressinificadas, transformando-se em conhecimentos úteis. Dentro do mesmo conteúdo ainda se desenvolveu atividade como produção de vídeo e slides e pinturas. (Figura 02).

Figura 02. Momento de aula e materiais produzidos.

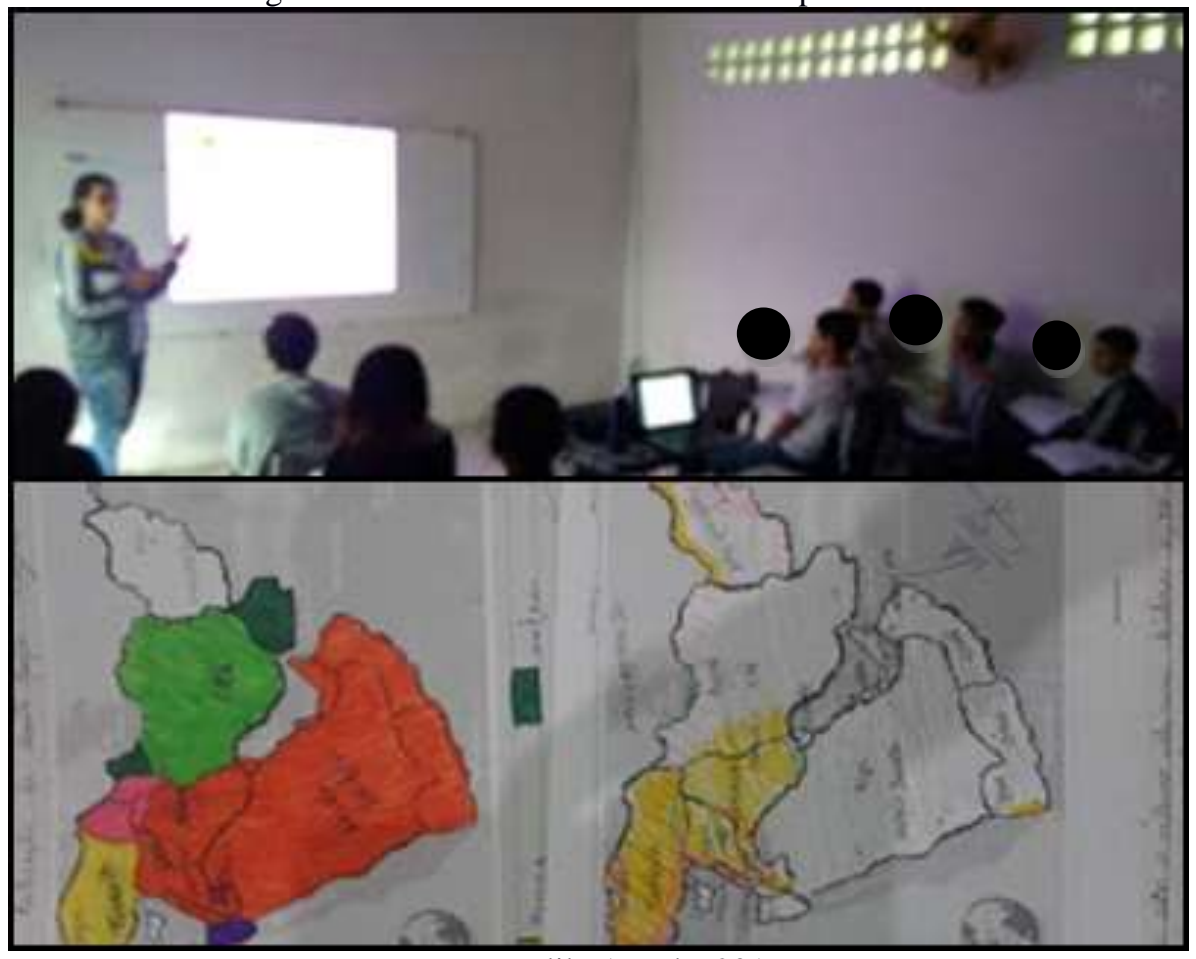

Fonte: Dalila Arruda, 2017. 
$\mathrm{Na}$ abordagem do tema continente africano, foram utilizados além das estratégias já mencionadas, o enfoque no uso de imagens para abordagem da paisagem do continente. Os discentes receberam fotos que mostravam diferentes contextos e aspectos, e a tarefa inicial consistia em observar e analisar a paisagem, em seguida fixá-la no mapa-múndi.

Atividade similar foi desenvolvida por Fantin (2005, p. 106), “Em seu encaminhamento, propõe iniciar o trabalho distribuindo aos alunos fotos das paisagens brasileiras, sem identificação do lugar que representam”. A autora coloca que esta é uma atividade de investigação bastante relevante, proporciona que o aluno resgate suas memórias a respeito de determinados lugares e conteúdos abordados de forma oral.

Nesta prática fora possível contextualizar problemas sociais e conflitos do espaço africano, que surgiram com o processo de colonização. Por meio das imagens os alunos mostraram que mesmo diante do que já havia sido refletido em sala, ainda permanecia em suas colocações resquícios de estigmas criados principalmente através das mídias.

Figura 03. Realização de atividade.

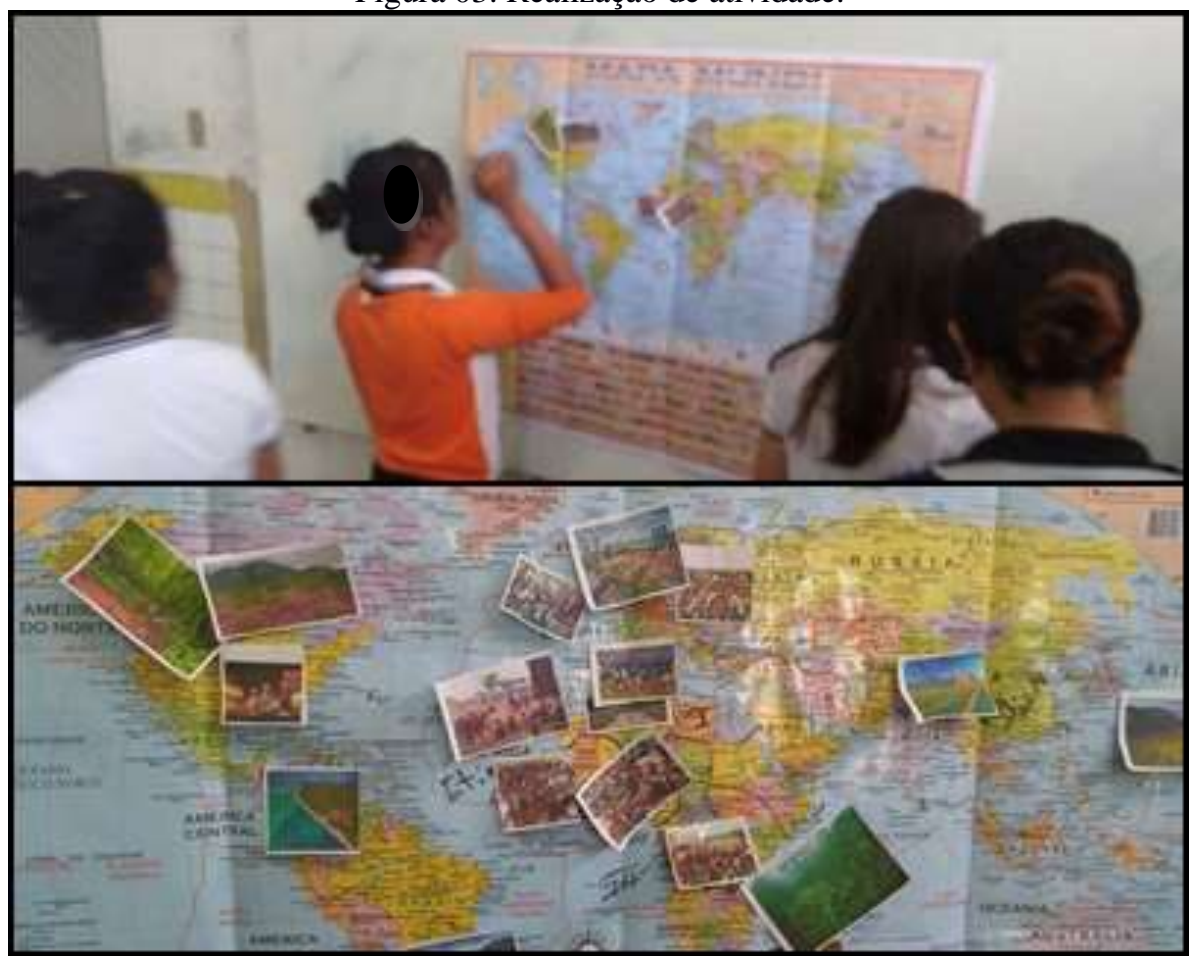

Fonte: Dalila Arruda, 2017.

Os alunos se mostraram apreensivo para saber se haviam colocado as paisagens nos lugares correspondentes. Houve constatações de erro, acertos e aproximações, e nisso, sobretudo se alcançou desenvolvimento do raciocínio geográfico. Assim, planejamos atividades de pesquisas bibliográficas, produções de textos, aulas expositivas dialogadas com enfoque mais direcionado para as diversidades encontradas naquela região. Como podemos 
ver na (figura 04), os momentos de intervenções e a apresentação de maquetes que foram produzidas pelos discentes.

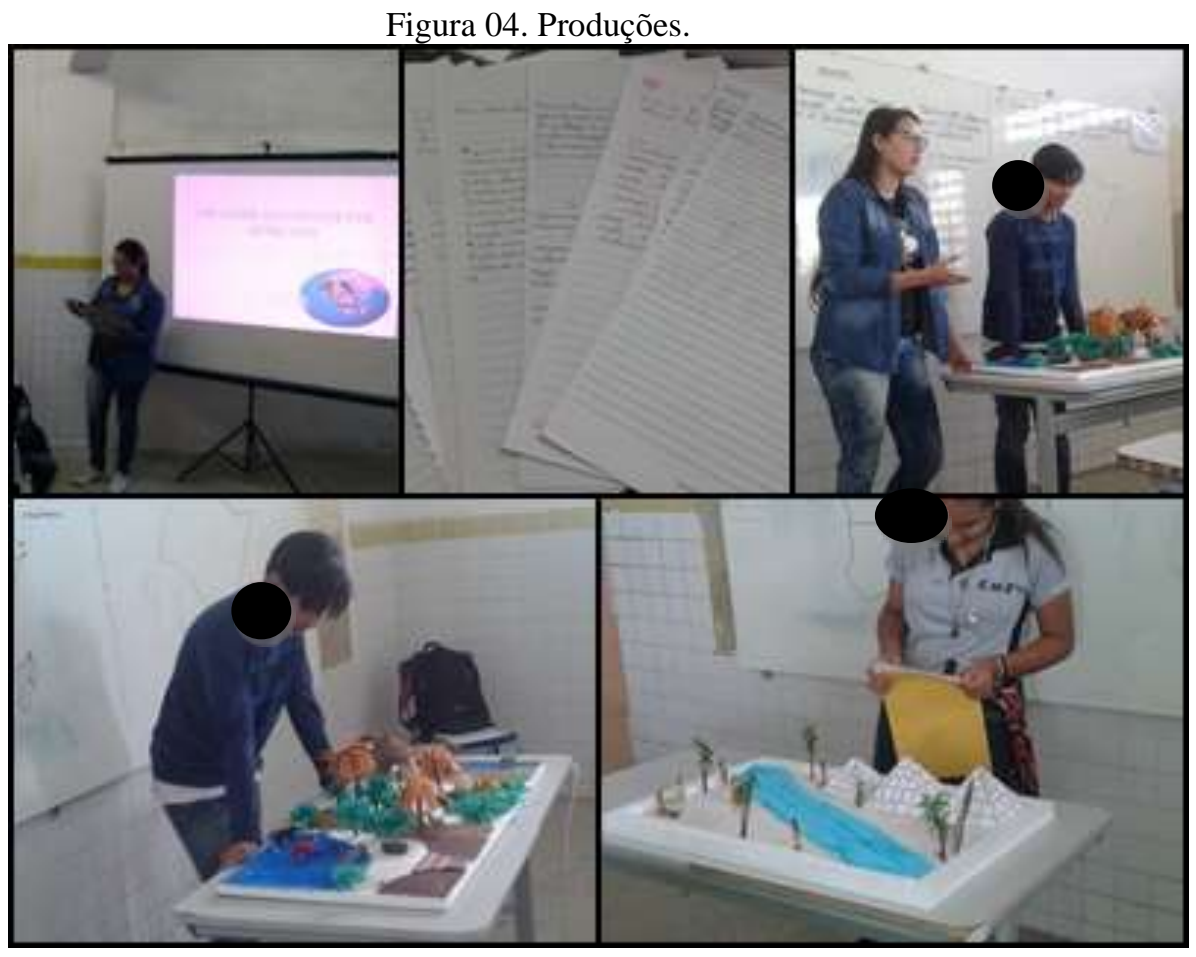

Fonte: Dalila Arruda/Jonas Marques, 2017.

Os alunos foram direcionados a realizarem pesquisas, e cada um escolheria um país da África para desenvolver seu levantamento, logo após esta atividade eles foram instigados a pensarem em formas para apresentar suas pesquisas. Foram oferecidas algumas sugestões, e alguns alunos produziram maquetes, como mostra a imagem acima.

Sobre o uso de maquetes no ensino, argumenta Almeida (2001, p,77), “ o uso de maquetes favorece a representação tridimensional para o bidimensional, por possibilitar o domínio do visual do espaço, a partir de um modelo reduzido". Contribuindo para construir uma noção da de dimensões e domínio de habilidades cartográficas.

Foram usados também recurso de vídeo, tirinhas, quadrinhos e fotografias. Após assistir ao vídeo os alunos tiveram a charge e a história em quadrinhos para externar os conhecimentos construídos ao longo das intervenções e reflexões sobre os temas. Trouxemos o diálogo para escala local, com intuito de promover uma aprendizagem por meio da paisagem percebida pelo aluno em seu espaço de vivencia.

A produção de charges e tirinhas promovera o despertar de uma visão crítica dos estudantes por meio da escrita e das representações gráficas, comprovando a contribuição 
destes recursos no ensino. Outro instrumento didático que se elegeu foi à fotografia, a partir da perspectiva da paisagem urbana como objeto de análise.

As fotografias são utensílios que podem auxiliar o aluno na captação das modificações na paisagem, que ocorre, sobretudo, com a ampliação da ocupação humana, e as diversas técnicas que o homem emprega sobre o espaço, concepção apoiada por Brandão (2013). Com base na análise fotográfica o aluno aguça a percepção da paisagem, se torna um agente investigativo no processo de ensino e aprendizagem.

Uma vantagem ao se usar a fotografia, é o fato de ser um recurso de fácil acesso, nisso, se a prática for bem planejada pode contemplar todos os alunos. Se ela for bem direcionada o docente facilitará a concepção da dinâmica espacial pelo aluno e despertará a identificação com o espaço ao qual ele se socializa. O mosaico abaixo, (figura 05) mostra o momento de socialização da atividade junto à turma.

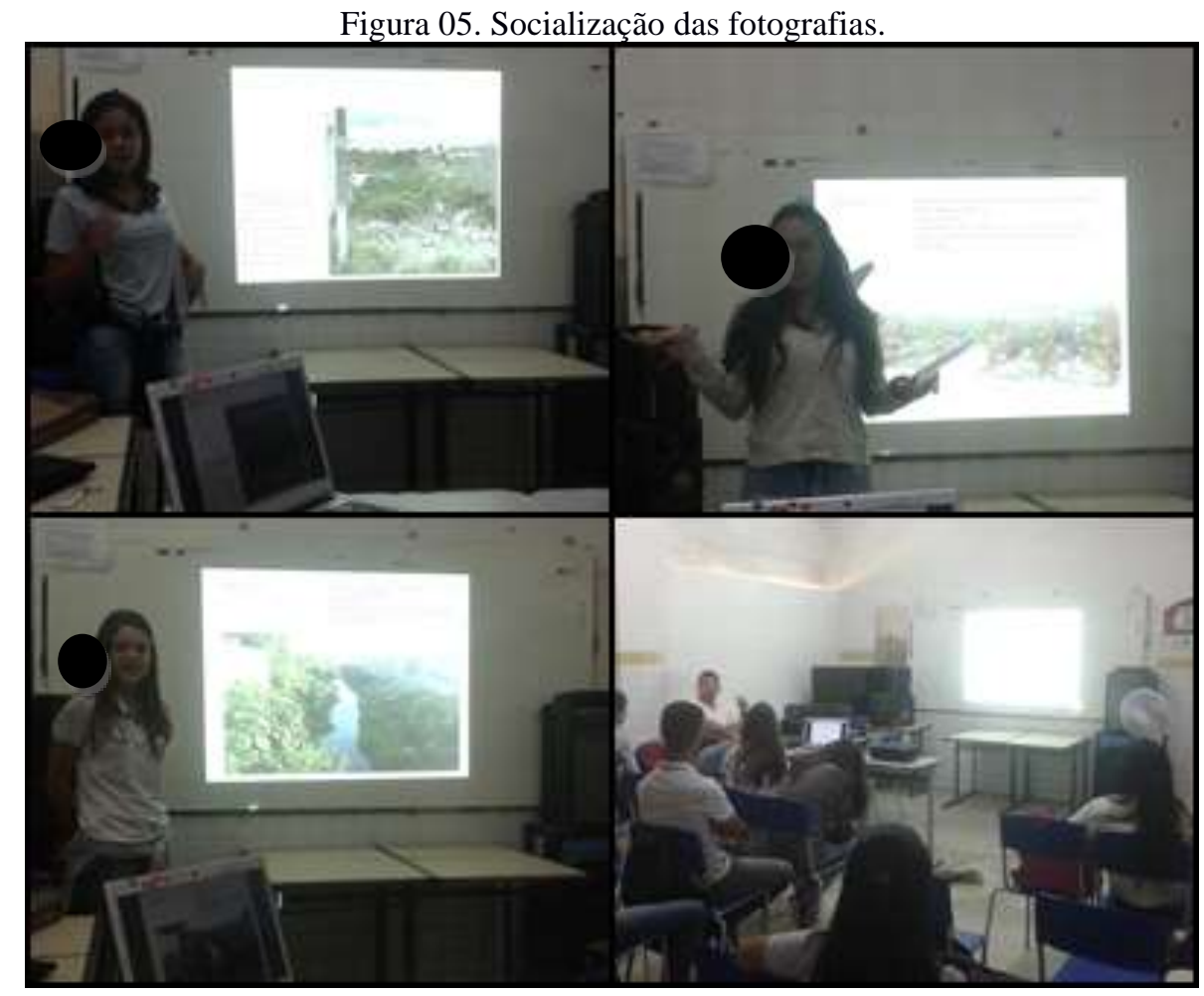

Fonte: Dalila Arruda, 2017.

Podemos inferir que durante o processo de construção desta atividade os alunos interagiram de forma espontânea, até por meio de redes sociais para dialogar sobre os materiais que estavam sendo elaborados. Os alunos mostraram domínio de conteúdo, e uma capacidade critico reflexiva aguçada. Nem todos tiveram a mesma desenvoltura, no entanto, sabemos que isso é normal em sala de aula, a heterogeneidade de concepções, representações sociais e cognições se desenvolvem de formas distintas em cada ser humano. 


\section{CONSIDERAÇÕES}

Durante a pesquisa procuramos refletir sobre alguns aspectos do ensino de Geografia e a utilização dos recursos didáticos como ferramentas facilitadoras no processo de ensino e aprendizagem da disciplina na escola básica, onde se constatou significativas contribuições destes recursos para a consolidação de práticas de ensino voltadas para o desenvolvimento do raciocínio geográfico crítico.

Práticas metodológicas herdadas da Geografia Clássica, ainda estão enraizadas na cultura educacional brasileira, consequentemente no ensino de Geografia, que nos dias atuais ainda promove práticas que despertam a apatia e desinteresse dos alunos. No entanto, a partir da utilização dos recursos didáticos de forma planejada e articulada as representações sociais dos discentes, constatamos que é possível superar alguns entraves das práticas de ensino clássicas.

Em relação aos resultados alcançados por meio dos projetos de intervenção pedagógicos, concordamos que as ferramentas didáticas são muito importantes para sistematização e apreensão da disciplina, pois utiliza de metodologias que envolvem o aluno no processo de ensino e aprendizagem, considera suas representações e possibilita espaço para que o estudante cresça intelectualmente.

Nem sempre conseguimos alcançar todos os alunos de uma turma de forma linear, criam-se algumas resistências inicialmente. Ao se constatar tais fatos durante a pesquisa, buscamos levantar conversas sobre as práticas que estavam se desenvolvendo, fazendo com que o aluno percebesse o quanto seria interessante fugir de práticas mnemônicas, e conhecer a Geografia por uma via mais representativa para sua vida cotidiana em sociedade.

Ao utilizar e produzir materiais didáticos como as imagens, fotografias, paródias, mapas, maquetes, entre outros, percebeu-se o quão significativos tornam-se simples ferramentas no processo educacional. Os alunos necessitam de utensílios que chame/prenda sua a atenção, somente o livro didático não é capaz de subsidiar os anseios desta nova realidade presentes nas escolas.

Reportando-se ao PIBID, este se configura como um projeto educacional de extrema importância para a formação inicial do docente, que proporciona a plena vivencia da sala de aula por meio dos projetos didáticos pedagógicos desenvolvidos no âmbito da escola básica. O projeto é uma excelente oportunidade para construção da identidade profissional como licenciando em Geografia. 
Em relação suporte oferecido pela pesquisa colaborativa no qual se configura a formação como um projeto coletivo, o apoio e orientações da professora orientadora, e no dia a dia escolar, a figura do professor supervisor consolidam as bases para efetivação destes resultados positivos. O trabalho em equipe, planejamentos, orientações, sugestões de leituras promovem a consolidação de uma formação inicial consistente.

As práticas pedagógicas resignificadas sob o viés da pesquisa-ação potencializam o trabalho do professor pesquisador, permitindo a consolidação de práticas mais reflexivas através do estudo das suas próprias experiências. Através dessa metodologia fora possível refletir sobre o rever contínuo das práticas em sala de aula e a importâncias desta conduta.

Nesse sentido este trabalho não pretende esgotar as discussões a respeito destas práticas, tendo em vista sua importância para o desenvolvimento de metodologias que promovam um ensino de Geografia cada vez mais significativo e integrador para os agentes envolvidos nesse processo cíclico que é a educação.

\section{REFERÊNCIAS}

ALMEIDA, R. D. de. Do desenho ao mapa: iniciação cartográfica na escola. Contexto, São Paulo, 2001.

BRANDÃO, I. D. N. Recursos didáticos: possibilidades de uso no ensino de Geografia. 2013. 86f. Trabalho de Conclusão de Curso (Bacharelado em Geografia) Universidade Estadual Paulista, Ourinhos, 2013.

BULGRAEN, V. C. O papel do professor e sua mediação nos processos de elaboração do conhecimento. Revista Conteúdo, v.1, n.4, p. 30-39. ago./dez. Capivari, 2010. ISSN 18079539.

CAVALCANTI, L. S. Geografia, escola e construção de conhecimentos. Papirus, ed. 17, São Paulo, 2010.

CASTROGIOVANNI. A.C. SCHAFFER, O; KAERCHER, N; GOULART, L. B; um globo em suas mãos: práticas para sala de aula. Penso. Porto Alegre, 2012.

CAVALCANTI, L. S. Geografia, escola e construção de conhecimentos. Papirus, ed. 17, São Paulo, 2010.

ENGEL, G. I. Pesquisa-ação. Educar em revista, n¹6, p. 180- 191. Curitiba, 2000.

Bimestral. ISSN 1084-0411.

FANTIN, M. Mídia-educação: aspectos históricos e teórico-metodológico. Revista Olhar de professor, ed. 14, p. 27-39. Ponta Grossa, 2005. Semestral. ISSN 1984-0187 
FISCARELLI, R. B. de O. Material didático: discurso e saberes. Araraquara: Junqueira \& Martins Editoras, 2008. ISBN 978-85-86305-52-8.

FRANCO, M. A. S. Pesquisa-ação e prática docente: articulações possíveis. In: __Pesquisa e educação: possibilidades investigativas/formativas da pesquisa-ação. Edições Loyola, São Paulo, 2012.

PONTUSCHKA, N. N. Representações e linguagens no ensino de Geografia. In: Para ensinar e aprender Geografia. p. 278-286. Cortez Editora. São Paulo, 2009.

SOUZA, S. E. O uso de recursos didáticos no ensino escolar. In: I Encontro de Pesquisa em Educação, IV Jornada de Prática de Ensino, XVIII Semana de Pedagogia da UEM: "Infância e Práticas Educativas”. Maringá, PR, 2007. Anais da Semana de Pedagogia da UEM. ISSN online 2316-9435.

TRIPP, D. Pesquisa-ação: uma introdução metodológica. Educação e pesquisa. V. 31, fasc. 3, p. 19-21. Revista da Faculdade de Educação da USP. ISSN: 1517-9702. 